\title{
An Exploratory Analysis of Computer Mediated Communications on Cyberstalking Severity
}

Stephen D. Barnes

Spears School of Business, Oklahoma State University

David P. Biros

Spears School of Business, Oklahoma State University

Follow this and additional works at: https://commons.erau.edu/jdfsl

Part of the Computer Engineering Commons, Computer Law Commons, Electrical and Computer Engineering Commons, Forensic Science and Technology Commons, and the Information Security Commons

\section{Recommended Citation}

Barnes, Stephen D. and Biros, David P. (2007) "An Exploratory Analysis of Computer Mediated Communications on Cyberstalking Severity," Journal of Digital Forensics, Security and Law. Vol. 2 : No. 3 , Article 1.

DOI: https://doi.org/10.15394/jdfsl.2007.1025

Available at: https://commons.erau.edu/jdfsl/vol2/iss3/1

This Article is brought to you for free and open access by

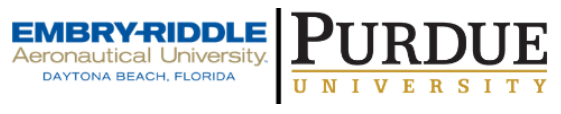
the Journals at Scholarly Commons. It has been accepted for inclusion in Journal of Digital Forensics, Security and Law by an authorized administrator of Scholarly Commons. For more information, please contact commons@erau.edu.

(c)ADFSL

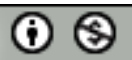




\title{
An Exploratory Analysis of Computer Mediated Communications on Cyberstalking Severity
}

\author{
Stephen D. Barnes \\ stephen.barnes@okstate.edu \\ Spears School of Business \\ Oklahoma State University \\ Stillwater, OK \\ David P. Biros \\ david.biros@okstate.edu \\ Spears School of Business \\ Oklahoma State University \\ Stillwater, OK
}

\begin{abstract}
The interaction between disjunctive interpersonal relationships, those where the parties to the relationship disagree on the goals of the relationship, and the use of computer mediated communications channels is a relatively unexplored domain. Bargh (2002) suggests that CMC channels can amplify the development of interpersonal relationships, and notes that the effect is not constant across communications activities. This proposal suggests a line of research that explores the interaction between computer mediated communications (CMC) and stalking, which is a common form of disjunctive relationships. Field data from cyberstalking cases will be used to look at the effects of CMC channels on stalking case severity, and exploring the relative impacts of CMC channel characteristics on such cases. To accomplish this, a ratio scaled measure of stalking case severity is proposed for use in exploring the relationship between case severity and CMC media characteristics, anonymity, and the prior relationship between the stalker and the victim. Expected results are identified, and follow-up research is proposed.
\end{abstract}

\section{INTRODUCTION}

This paper reports on current work in progress to understand the impact of computer mediated communications (CMC) channels on disjunctive online relationships. Following a line of research into the impact of the Internet on the development of interpersonal relationships, prior research has shown that use of computer-mediated communications (CMC) features can amplify and/or accelerate the development of such relationships (Bargh 2002; Bargh et al. 2002; McKenna et al. 2002; Hian et al. 2004), contrary to the expectations of early CMC and information systems researchers (Daft et al. 1986; Walther 
1996; Dennis et al. 1998). Much of the past research on CMC and associated theories has been studied in relatively benign contexts, contexts that may be considered "conjunctive" (Cupach et al. 2004) Thus there are opportunities to study CMC usage and concepts in less benign environments as well. Our work looks at relationships that have turn sour or disjunctive, to understand what effects, if any, CMC channels have on such relationships. Cyberstalking is such a disjunctive environment, one with substantial opportunities for research.

This leads to the following question: If the Internet and CMC tools can accelerate or amplify the development of interpersonal relationships, what is its corresponding ability to amplify (or dampen) the impacts when a relationship goes through the process of dissolution? This is of course an impossibly broad question to answer, as there are a substantial number of reasons for the dissolution of relationships (Cupach et al. 2004). Thus this research effort limits the scope of the question to one of particular interest to academics, legal and clinical practitioners, and Internet service providers: stalking, or more precisely, cyberstalking. Stalking is one common outcome of the process of dissolution of a relationship, and is characterized by harassment of one person (usually the person initiating the dissolution) by the other. Such harassment can take one of two common forms: obsessional relational intrusion (ORI, also known as hyperintimacy), in which the pursuer attempts to restore or strengthen the relationship, or stalking, where the pursuer is attempting to punish the object of pursuit (Cupach et al. 1998, 2004). Stalking and ORI are thus useful as clearly defined forms of disjunctive relationships that can be used as the basis for research into the impacts of CMC channels on disjunctive relationships generally.

In addition, we propose to extend this, looking at three characteristics of CMC channels and their impacts on cyberstalking cases. Te'eni (2001) suggests three dimensions to communications media that may affect the medium's ability to convey stalking messages: interactivity, richness (e.g. support for verbal communications), and adaptability. Adaptability is closely related to the distribution mechanism for messages on a medium, e.g. whether the medium is typically private (peer-to-peer messages) or public (e.g. a blog). An additional characteristic of some CMC media is the ability to provide the sender with an effective form of anonymity (Berthold et al. 2000), which may impact the cyberstalking victim in various ways. This proposal suggests means for exploring these interactions, as a prelude to more focused research on the topic in the future.

The remainder of this paper is organized as follows. Section 2 introduces the reader to stalking and cyberstalking, and introduces a number of dimensions of stalking that are used in this research. The first classifies stalking cases by the prior relationship between the stalker and the victim. The second identifies the location of the relationship, specifically if it an online or offline relationship. 
A brief discussion of known CMC impacts on relationships follows. Section 3 develops our model, and details the research hypotheses proposed for testing with the available cyberstalking case data. Section 4 introduces the cyberstalking case histories planned for use in this research, and details the calculation of an index of case severity using the analytical hierarchy process for use as the dependant variable. A testing methodology is also proposed in this section. Section 5 follows with some conclusions, with comment on the limitations of this research and suggestions for future research.

\section{BACKGROUND}

\subsection{Stalking, Cyberstalking, and Online Harassment}

Cupach and Spitzberg (2004) introduce their book on obsession and stalking with the concept that interpersonal relationships may take on two forms. First, "when individuals pursue mutual activities and states, their shared relationship may be considered conjunctive in structure. Conversely, when relationships are non-mutual, they may be considered disjunctive in structure" (Cupach et al. 2004 p3). Many other forms of relationships are disjunctive, but as Cupach and Spitzberg observe, "few seem so prototypical of disjunction as stalking and obsessive relational intrusion" (2004 p3).

The academic literature generally defines stalking as "a series of actions directed at one individual by another that taken as a whole amount to unwanted persistent personal harassment" (Sheridan et al. 2001b p152). Goode (1995) suggests that stalking is a pattern or "course of conduct" of intentional harassment intended to cause emotional distress. ORI consists of excessive efforts on the part of the perpetrator to develop a relationship with a victim, often to the extent that normally positive acts take on negative connotations in the perception of the victim. The differences between ORI and stalking are only minimally important for the purposes of this study (Harmon et al. 1995) as it is the perception of the victim that practically (and legally) determines if harassment is taking place (Cupach et al. 1998, 2004). This paper will use a somewhat relaxed definition of the term stalking, which includes both "classic," or criminal, stalking and more aggressive forms of ORI, unless otherwise noted.

Cyberstalking is stalking perpetrated exclusively or largely with computermediated communications (CMC) and/or a wide variety of other online applications and services (Spitzberg et al. 2002). ${ }^{1}$ CMC can provide support for offline stalkers, as a tool in their kit (Spitzberg et al. 2002), or a cyberstalker can operate purely online, even when the victim is not a regular user of the Internet. The latter is demonstrated in the case of Gary S. Dellapenta, who severely traumatized his victim via personal ads placed on the

\footnotetext{
${ }^{1}$ In general usage, the term cyberstalking also encompasses some cases better classified as online incidents of ORI.
} 
Internet (Miller 1999). Cyberstalking has recently become a recognized phenomena (Miceli et al. 2001; D'Ovidio et al. 2003), but there have been only a few pilot studies of its prevalence and impacts on victims (Spitzberg et al. 2002; Finn 2004; Alexy et al. 2005).

\subsection{Dimensions of Stalking}

For the purposes of this paper, three dimensions of stalking are important. The first is the nature of the prior relationship between the stalker and the victim. Often, stalking originates out of the dissolution of an intimate relationship, but it can also evolve from all other forms of relationships (Sheridan et al. 2001b; Spitzberg 2002; Cupach et al. 2004). Emerson et al. (1998) suggest that stalking is most likely to originate as a relationship begins or ends, and that most cases of stalking are a dynamic process that evolves from a normal relationship through hyperintimacy and ORI into classic stalking. This is supported by the evidence, which suggests that upwards of $50 \%$ of classic stalking cases resulted from the dissolution of some form of intimate relationship, either as spouses, sexual partners, or a dating relationships that lasted more than a few weeks (Tjaden et al. 1998, 2000; Spitzberg 2002). Sheridan et al. (2001a) captures a concise typology of relationship types, providing for five main categories:

- Domestic violence stalking by a current or former intimate partner.

- Domestic violence stalking by another family member.

- Stalking by friends/acquaintances.

- Stalking by strangers/Erotomania.

- Stalking by unknown or anonymous stalkers.

This paper uses Sheridan's typology to characterize the relationships between stalker and victim in this research, with a further extension representing the context in which the relationship began, as follows.

The second dimension of importance here is the original context of the relationship. This dimension is used to identify where the stalker meets and interacts with the victim. Traditionally, this meant work, school, or church, but for this research the crucial aspect is did the relationship exist solely online, or did the stalker and victim ever meet and have an offline relationship. Today, some of the most popular web sites on the Internet are social networking sites, some of which are explicitly designed to facilitate the process of initiating relationships. McKenna et al. (2002) reported on the history and evolution of such online relationships, and the progression from email and internet relay chat (IRC) to the telephone to meeting in person. Bargh et al. (2002) and McKenna et al. (2002) together show that use of CMC allows individuals to 
more easily present their "true selves" and, on the receiving side, map that to the receivers ideal of the person presented. This accelerates the formation of relationships, and often leads to long term friendships and offline intimacy (McKenna et al. 2002). Hian et al. (2004) demonstrated that contrary to expectations, computer mediated communications actually accelerated the development of relations over face to face communications in zero-history dyads in a organizational environment.

The third dimension addresses the form or severity of the harassment (Cupach et al. 1998; Sheridan et al. 2001b; Spitzberg 2002). This third dimension is postulated here to be related to the first two, and will be used to generate the primary dependant variable for our analysis. We will review this dimension in more detail below.

\subsection{Harassing Acts}

The true measure of the severity of stalking cases is the psychological impact on the victim. Data for this is not readily available without an extensive data collection process, so a proxy for this measure is required. Purcell et al. (2004) show a significant connection between the frequency and number of harassing acts, threats, and aggression and the resulting psychological impact on the victim. Such harassment can, of course, cover a very broad range of acts, and does. Spitzberg (2002), in a significant meta-analysis, developed a typology of stalking based on the actions of stalkers found in his literature review. Spitzberg grouped the actions into seven categories of roughly increasing severity, as follows:

\section{Hyperintimacy}

2. Pursuit, Proximity, and Surveillance

3. Invasion

4. Proxy Pursuit/Intrusion

5. Intimidation and Harassment

6. Coercion and Constraint

\section{Aggression}

Hacking and impersonation online were not included in Spitzberg's typology details (Spitzberg 2002). Note here that online technologies are tools not strategies, and can be used to support virtually all of Spitzberg's strategies. This paper uses Spitzberg's categories as the basis for our case severity index, as described further below. 


\subsection{Case Severity in Cyberstalking}

Purcell et al. (2004) show a significant connection between the frequency and number of harassing acts, threats, and aggression and the resulting psychological impact on the victim. After dividing their survey sample of stalking cases into short (less than two weeks) and long duration cases, they showed that longer cases were more severe in all categories, and that two measures of psychological morbidity, the 28-item General Health Questionnaire (Goldberg et al. 1979), a screening measure of current general psychiatric morbidity, and the Impact of Event Scale (Horowitz et al. 1979), a measure of post-traumatic stress reactions associated with victimization, were elevated. Comparison of both morbidity measures between short cases and non-stalking survey respondents were not significantly different (Purcell et al. 2004). This leads to the conclusion that increases in duration, action frequency, threat volume, and aggression can be associated with increases in psychological impacts on the victims. This paper utilizes Purcell's conclusions to developing an index of case severity, which is based on the presence (or not) of various actions and threats in the case record.

A review of the literature addressing the seriousness or severity of specific stalking/cyberstalking incidents in comparison to other incidents produced only three other papers. A meta analysis of stalking research by Rosenfeld (2004) found that only two studies up to that time differentiate between minor and serious violence, and none systematically studied the rate of homicide in stalking cases (Rosenfeld 2004 p12). Brewster (2000 p45) used injury as a proxy for violence, but did not differentiate between small cuts and bruising and more severe injuries such as broken bones or wounds requiring stitches. Rosenfeld and Harmon (2002) defined serious violence as cases in which actual or attempted harm was potentially life-threatening or would result in significant bodily harm.

Other papers that deal with the issue of severity of cases address the legal status of the incident: was the incident serious enough to be labeled a crime. As stalking (and cyberstalking) are made up of many smaller actions, there has been an ongoing debate about what constitutes the crime of stalking, and this is reflected in the literature (Dziegielewski et al. 1995; Goode 1995; Ellison et al. 1998; Tjaden et al. 1998; Sheridan et al. 2001b; Bocij 2002; Sheridan et al. 2002; Brenner 2004; Phillips et al. 2004; Roberts et al. 2006). Unfortunately, these works assume a binary outcome, crime or not, and do not measure the degree of impact on the victim.

\subsection{Impacts of Computer Mediated Communications Channels}

Bargh postulates that the amplification of relationship development occurs as the result of two main factors. First is the ability of the Internet to allow individuals with common interests to find each other quickly and easily, even if widely separated geographically (what can 
be called the search capability of the Internet). As mutual interests are at the core of stable relationships, this search capability accelerates the process of discovery of shared mutual interests. Second, use of Internet $\mathrm{CMC}$ tools allow the speaker to filter out aspects of the self that might be detrimental to the initial development of a relationship, but that can be overlooked once a common bond has been formed. This is shown to accelerate the disclosure of the speaker's "true" or inner self, leading to an accelerated strengthening of the relationship (Bargh et al. 2002; McKenna et al. 2002).

Similar effects from use of CMC media are shown to have a negative effect on commercial negotiations (Thompson et al. 2002), have positive long term effects on social involvement and psychological well-being among new Internet users (Kraut et al. 2002), and allow people with extreme perspectives on any topic to find others of a like mind, leading to the reinforcement of such extremist views (Glaser et al. 2002). Spears et al. (2002) note that CMC effects can reinforce such things as "group think" phenomena within all groups, with particularly worrisome consequences for extremist and/or antisocial groups (Glaser et al. 2002). The Glaser et al. study also shows the power of the Internet and $\mathrm{CMC}$ tools to allow research into topics that would otherwise be difficult or impossible to research (Glaser et al. 2002).

\section{RESEARCH MODEL \& HYPOTHESIS}

The formal research model explored in this paper is shown in Figure 1, and consists of two main elements. The first element addresses the interaction of the type and intensity of the prior relationship between the stalker and the victim, and the context in which the relationship existed, where the latter is divided into online and offline relationships. This interaction is the subject of the first hypothesis under study, and underlies all of the following work. A series of additional hypotheses extend the analysis of this interaction to look into postulated differences related to intimacy level and anonymity on the part of the stalker. The second element is dependant on a showing of an interaction, and attempts to explore a trio of the various characteristics of CMC that may have an impact on cyberstalking. This effort thus begins the task of pulling apart CMC characteristics to see which has the most significant impacts on this type of relationship. This research model is elaborated in the following sections. 


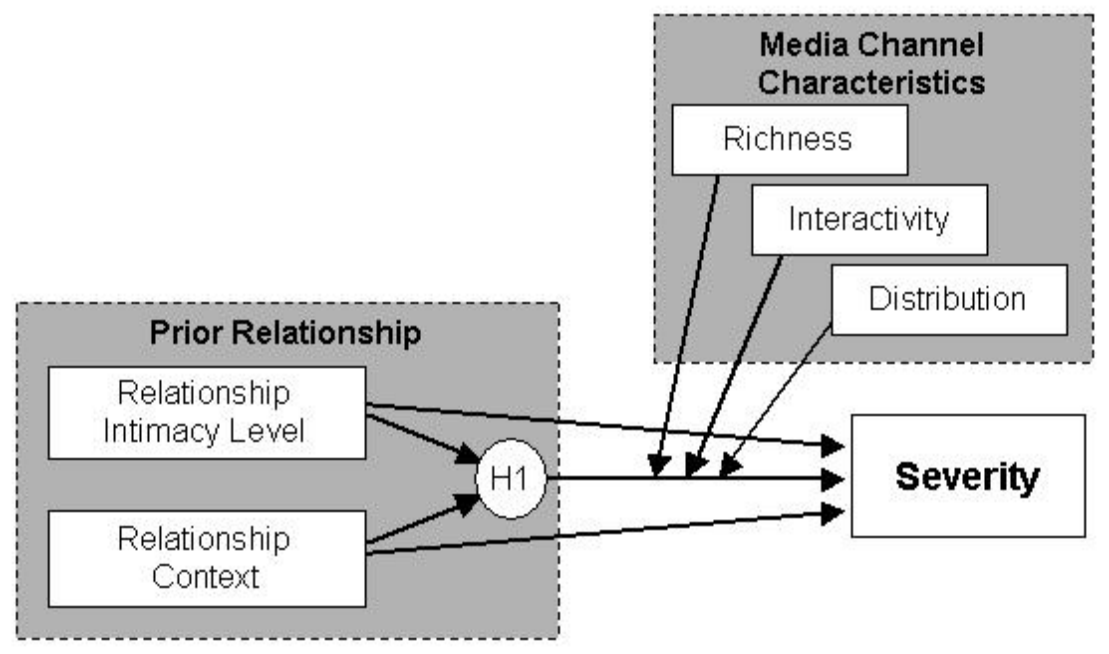

Figure 1: Basic Research Model

\subsection{Relationship Intimacy and its Context}

Given the potential for CMC impacts on relationships generally (Bargh 2002; Bargh et al. 2002; McKenna et al. 2002), it is reasonable to speculate that relationships that originate and remain online will also be affected by some form of CMC effect when they turn acrimonious and disjunctive. This is further supported with the study by Thompson and Nadler (2002) that showed that adversarial negotiations were hindered by exclusive use of CMC communications channels, implying that the use of CMC channels will affect at least some types of disjunctive relationships. This leads us to postulate that there is a likelihood that differences in case severity will be noted when online and offline cases of stalking are compared.

While arguments can be made for either an increase or a decrease in case severity resulting from use of CMC channels, it appears that on balance, a decrease is more likely. The argument for an increase is based on extending the work of Bargh, McKenna, and colleagues (Bargh 2002; Bargh et al. 2002; McKenna et al. 2002), which suggest that $\mathrm{CMC}$ usage accelerates the relationship cycle, along with the findings of Thompson et al. (2002), and which suggests that CMC usage amplifies adversarial effects in a relationship. Conversely, purely online relationships tend to move offline as they strengthen (McKenna et al. 2002), suggesting that the stronger the relationship, the less likely it is to remain a purely online relationship. Assuming that stronger relationships lead to more severe cases of stalking, online relationships that move offline will tend to bias central tendency 
measures of severity, lowering values for online cases and raising it for offline cases. Unless this potential confound can be measured and accounted for, there is the potential that it will dominate any CMC effects in the other direction.

Two simple steps can be taken to reduce this problem when working with field data. First, offline cases where the stalker is identified as a former spouse can be eliminated, as it is not possible for couples to marry without meeting offline. This eliminates many offline cases with the strongest relationships. Second, any measurement of case severity must reflect the potential for or actual occurrence of physical aggression and violence in the case. Such actions are not possible online, but should account for a portion of any reasonable measure of case severity. Thus we intend to exclude offline cases that include occurrences of physical aggression and violence from the offline comparison group.

Thus we propose the following hypothesis, suggesting that online relationships reliant on $\mathrm{CMC}$ tools will lower case severity for intimate relationships, while having a weaker or insignificant impact on other types of relationships.

$\mathrm{H} 1$ : Online relations are negatively related to case severity for intimate relationships.

Figure 2 illustrates the postulated outcome of a test of this hypothesis, where $\mathrm{H} 1$ is represented by the differing slopes of the lines shown.

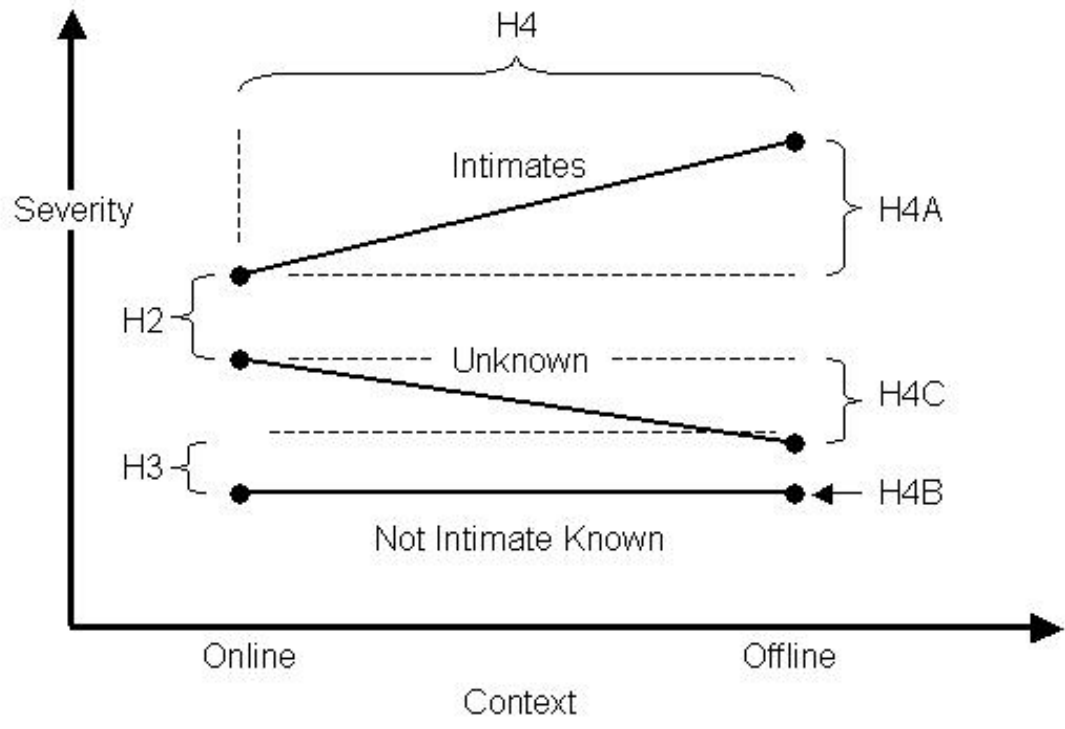

Figure 2: Predicted results of the Relationship - Context Interaction 


\subsubsection{Main Effects: Intimacy Level}

One of the more reliable findings about stalking is that the level of prior intimacy between the partners is a good predictor of violence (Cupach et al. 2004 p135, summarizing 14 other works). Former intimates are much more likely than others to employ aggression against their victim. Purcell et al. (2004) showed that differences based on duration were correlated with the type of relationship, with longer cases associated with stronger psychological effects and greater intimacy. Taking a different perspective, the following hypothesis ignores the time domain and looks only at the reported level of intimacy and its effect on case severity.

$\mathrm{H} 2$ : Former relationship intimacy level is positively associated with severity.

\subsubsection{Main Effects: Anonymity}

Not knowing the identity of a stalker is likely to increase the level of fear in the victim. Further, anonymity removes the potential for negative consequences to the stalker, provided the anonymity can be maintained (Connolly et al. 1990). Given the effective ability of CMC to hide true identities, a desire for anonymity on the part of a stalker is likely to influence both their choice of communications media, and the impact on the victim. Further, the more an anonymous stalker knows about a victim, the more severe the impact is likely to be. Such would be the case if a former intimate successfully stalks a victim anonymously. This, if CMC tools can provide effective anonymity, the impact on a case should be to increase severity. This leads to the following hypothesis:

H3: Anonymity is positively associated with case severity.

\subsubsection{Main Effects: Context}

While we have postulated an interaction between the intensity of a relationship and its use of CMC channels, it is also apparent that there may be significant main effects both on relationships generally and on various types of relationships. These flow directly from the finding of Bargh, McKenna, and colleagues (Bargh 2002; Bargh et al. 2002; McKenna et al. 2002) and others (Kraut et al. 2002; Spears et al. 2002; Thompson et al. 2002; Tyler 2002) showing that Internet usage can have both positive and negative effects. Thus we propose the following tests of the effects of CMC usage on relationships generally, and on specific subsets of relationship types. Each of the postulated results of these hypotheses are illustrated in Figure 2 above.

H4: Offline relationships will be more severe than online relationships.

H4A: Offline intimate relationships will be more severe than online intimate relationships. 
H4B: Offline not-intimate known relationships will NOT be different from Online not-intimate known relationships.

H4C: Offline unknown relationships will be less severe than online unknown relationships.

\subsection{CMC Channel Characteristics}

Presuming that the previous postulates hold, a logical follow-up question is what characteristic of CMC tools have the largest impact on the link between CMC usage and case severity. Te'eni, in a significant review, suggests that three characteristics of channels that are likely affect the senders choice of medium (relative to some intended strategy): channel capacity, interactivity, and adaptiveness (Te'eni 2001 p271). Channel capacity in this context is not the raw bit rate, but rather the ability of the channel to support a variety of verbal and non-verbal cues and hints that a perceptive receiver can use to interpret the message content (Te'eni 2001 p271; Kock 2004). Interactivity relates to the ability of the channel to support real-time dialog between the parties (Te'eni 2001). Finally, adaptiveness in Te'eni's (2001) terms is the ability of a medium to tailor a message for a given recipient. Thus blogs and bulletin boards are less adaptive than a personal email. Te'eni cites only one study of adaptiveness, Adams et al. (1993), suggesting a paucity of research in this area.

While not identical, the distribution mechanism of a message provides a close proxy for adaptability. We tentatively divide this distribution dimension into two halves, public and private, that can also be thought of as sender driven and recipient driven. This division is intended to capture the difference between CMC media that are effectively private (or peer-to-peer), with the sender specifically identifying the recipients, and those that are distributed more widely (e.g. to the public), with the recipient choosing to subscribe to the channel and further choosing to read (or listen to) each message or not.

Table 1: CMC Channel Characteristic Map

\begin{tabular}{|c|c|c|c|c|}
\hline & \multicolumn{2}{|c|}{ RICHNESS: VERBAL } & \multicolumn{2}{|c|}{ Richness: Text } \\
\hline & Interactive & Delayed & Interactive & Delayed \\
\hline $\begin{array}{l}\text { Distribution: } \\
\text { Private }\end{array}$ & $\begin{array}{l}\text { FTF, Phone, } \\
\text { Video Conf, } \\
\text { Webcam }\end{array}$ & Voice Mail & $\begin{array}{l}\text { IM, ICQ, } \\
\text { (Hacking?) }\end{array}$ & $\begin{array}{l}\text { Email, SMS, } \\
\text { Postal Mail, } \\
\text { Ecards }\end{array}$ \\
\hline $\begin{array}{l}\text { Distribution: } \\
\text { Public }\end{array}$ & None Known & $\begin{array}{l}\text { Broadcasting, } \\
\text { Movies, } \\
\text { YouTube }\end{array}$ & $\begin{array}{l}\text { Chat, Game } \\
\text { Forums }\end{array}$ & $\begin{array}{l}\text { Blogs, Lists, Msg. } \\
\text { Boards, Websites, } \\
\text { Ebay ratings, } \\
\text { Usenet, Wiki } \\
\text { Entries }\end{array}$ \\
\hline
\end{tabular}

Table 1 shows the association of a variety of current CMC tools with these three channel characteristics. Note that there are no known applications that fit the public verbal interactive category, and that our data (discussed below) does 
not contain any cases that fall into the public verbal delayed category, leaving this research able to explore only the remaining six categories shown. We address each of these three characteristics in turn in the following paragraphs.

\subsubsection{Richness}

Kock (2004) divides media types into two groups, those that support natural speech (FTF, video, phone) and those that do not (i.e. text-based). We will label this characteristic of the channel as its richness (with apologies to earlier researchers (Daft et al. 1986; Carlson 1995; Zigurs et al. 1998) who suggested a wider range of variability in this domain). We postulate that such a division will have an impact on disjunctive relationships and stalking, and that the direction of the affect will show that use of verbal channels increases case severity. Since the data source we are using for this research provides an opportunity to test this empirically, we propose the following hypothesis:

H5: Use of verbal media in a case will be more severe than cases using only text media.

Figure 3 illustrates the predicted impact of this richness construct on stalking case severity.

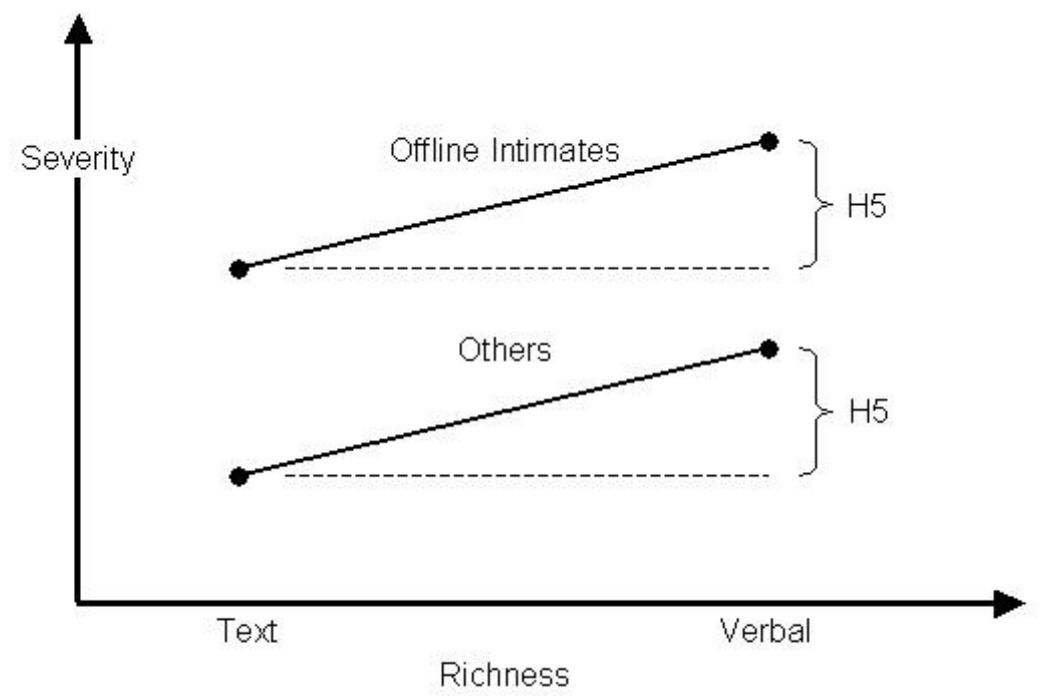

Figure 3: Predicted impact of Richness on Case Severity

\subsubsection{Interactivity}

Second, we can test the impacts of interactivity, or channel delay, on case severity, by comparing cases that use synchronous or real-time channels versus those that use asynchronous or delayed channels. 
Dennis and Kinney (1998) tested channel delay as a part of a larger experiment, and found that delayed channels had a more significant impact on less equivocal tasks. We hypothesize that there is a similar correlation between real-time channels and more severe cases of stalking.

H6: Use of interactive media in a case will be more severe than cases using only delayed media.

Figure 44 illustrates the predicted impact of this interactivity construct on stalking case severity.

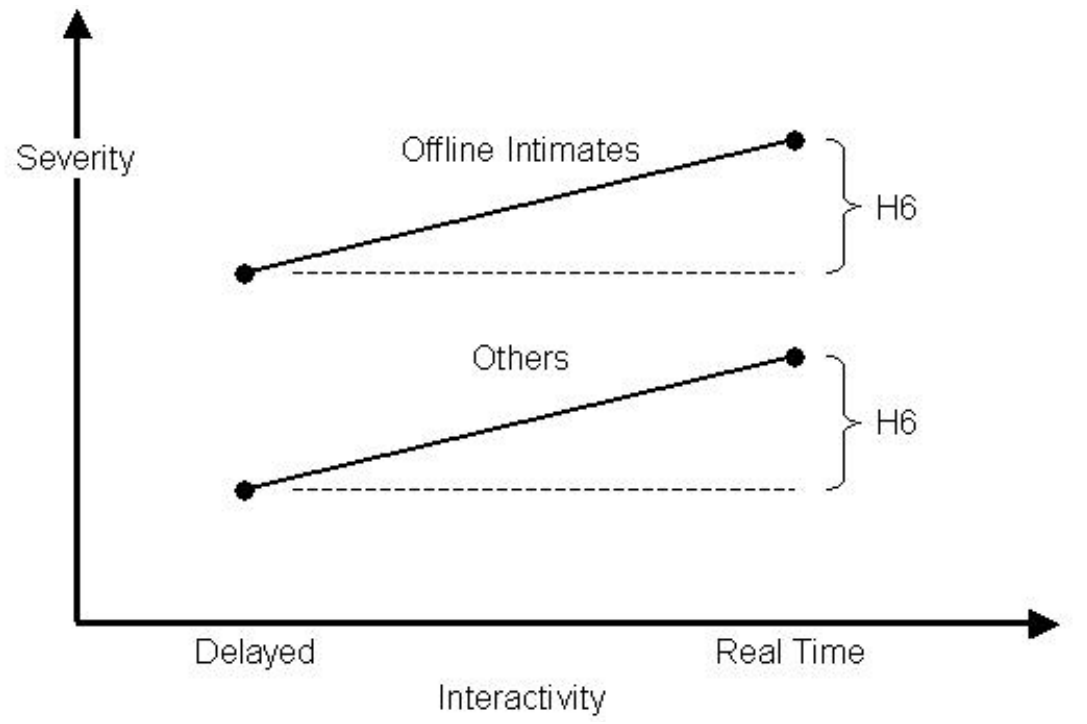

Figure4: Predicted impact of Interactivity on Case Severity

\subsubsection{Distribution}

As noted above, distribution reflects the ability of the sender to direct a message to a controlled list of recipients. By assigning each media type into either the public or private domain, we postulate that use of private media types will increase the impact of stalking on victims, leading to the following hypothesis:

H7: Use of Private media in a case will be more severe than cases using only public media.

Figure 5 illustrates the predicted impact of this distribution construct on stalking case severity. 


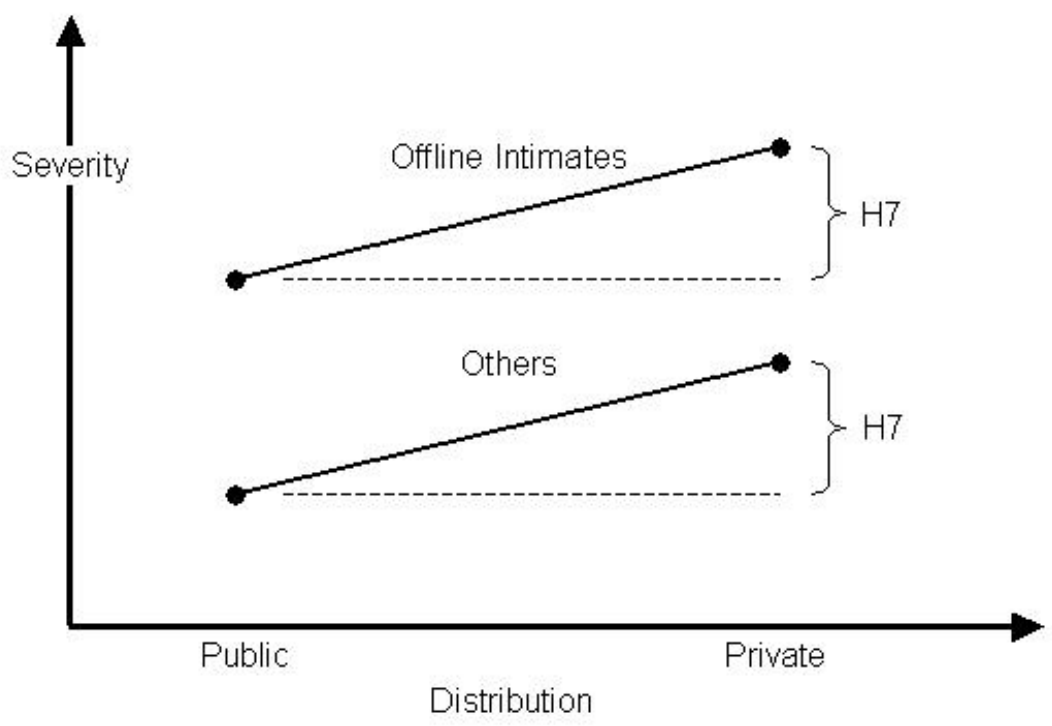

Figure 5: Predicted impact of Distribution on Case Severity

\section{METHODOLOGY}

\subsection{Data Source \& Description}

We were given 1225 case records summarizing cyber harassment and cyberstalking incidents over the time period from 2001 to 2005 from the records of a harassment victim's advocacy group, Working to Halt Online Abuse (WHOA) to work with for this study. WHOA regularly works with victims refereed by law enforcement agencies otherwise unable to meet the victim's needs, and in turn refers victims to appropriate law enforcement agencies when a case is sufficiently serious. After the initial coding, 66 cases were not deemed harassment (most were spam problems), and were dropped from the data, leaving 1159 harassment cases. All of the information is selfreported by the victims, as recorded and summarized by WHOA'a volunteer advocates (case workers). Included are case results as noted by the advocate.

The WHOA data records the communications media used for the first harassing message, other media used, other places the victim reported the harassment (e.g. law enforcement), a summary of the case results, and the year the case occurred in. Each case contains some demographic information on the victim's age, gender, marital status, occupation, race, and state or country of residence. In addition, each case contains some information about the stalker, where known to the victim, including age, gender, and state or country of residence. 


\subsection{Case Severity - The Dependent Variable}

The goal of a stalker is to influence the affective state of the victim, either by persuasion to their point of view, or by threats. We make the assumption, supported by research into classic stalking (Emerson et al. 1998; Cupach et al. 2004; Purcell et al. 2004), that an increase in the number and severity of stalking events translates into an increasing impact on the victim, and, working backward, suggest that severity of the case can be used as a proxy for the impact on the victim. Case severity is the dependent variable for this study. The proposed measure is based on the categories of stalking activities and strategies developed by Spitzberg (2002), augmented with categories suggested by Sheridan et al. (2001b), and on a preliminary review of the limited data recorded in the case summaries provided by WHOA.

The WHOA case data will be used to develop three category scores, based on 1) the actions taken by the stalker, 2) any threats present in the case summary, and 3 ) on the results noted by the WHOA advocate. These category scores are weighted and summed to provide the overall case score. To implement the proposed approach, each case is scored for the presence of each of specific types of activities, threats, or results, respectively, within each category as described below. Analytical Hierarchy Process (AHP) is used to determine weights within each category and for the category weights (Saaty et al. 2001; Taylor 2004).

\section{FINDINGS}

Hypothesis $\mathrm{H} 1$ postulated that severity of offline cases would be more severe than those that were online. Accounting for relationship intimacy and relationship context interaction, the context main effect term is significant $\left(\mathrm{F}_{(1}\right.$, ${ }_{783)}=16.481, p<0.001$, power at $\alpha=0.05$ is 0.982 ). Hypothesis $\mathrm{H} 2$ suggested a difference in case severity based on the level of intimacy in the relationship. Accounting for relationship intimacy and relationship context interaction, the intimacy main effect term was significant $\left(\mathrm{F}_{(2,783)}=4.493, p=0.011\right.$, power at $\alpha=0.05$ is 0.768 ). Hypothesis $\mathrm{H} 3$ addressed anonymity as a factor in case severity. To test this, a $2 \times 6$ factorial design ANOVA was employed to contrast the anonymity variable described in Chapter IV with the cells of the combined relationship intimacy-context interaction described above. This test failed to show any significant interactions $\left(\mathrm{F}_{(4,684)}=0.801, p=0.525\right.$, power at $\alpha=0.05$ is 0.258 ). Anonymity as a main effect was not a significant after accounting for relationship intimacy and context $\left(\mathrm{F}_{(1,684)}=0.806, p=0.369\right.$, power at $\alpha=0.05$ is 0.146 ), and a univariate test of anonymity was also not significant $\left(\mathrm{F}_{(1,684)}=1.40, \mathrm{p}=0.237\right.$, power at $\alpha=0.05$ is 0.219$)$.

The series of hypotheses under $\mathrm{H} 4$ explored the role of relationship context on cyberstalking cases. The analysis used a $2 \times 3$ factorial design in an ANOVA framework to test for this interaction. The results showed a significant 
interaction term providing support for hypothesis H4. The six interaction cell means were compared using Bonferroni's correction for multiple comparisons, and only the offline intimate cell was consistently different from the other cells. Hypothesis H4A postulated that offline intimate cases would be more severe than online intimate cases. This hypothesis is supported $(p=0.010)$, as shown in Table 14. In the intimate case, offline cases are more severe, likely due to the closer nature of the relationship and the feasibility of offline harassment activities. Hypothesis H4B posited that offline acquaintance cases would not be different from online acquaintance cases. This hypothesis is supported with this data $(\mathrm{p}=0.299)$. Hypothesis $\mathrm{H} 4 \mathrm{C}$ suggested that offline stranger cases would be different from online stranger cases. This hypothesis is not supported with this data $(\mathrm{p}=0.153)$. We note that there were very few cases in the online stranger category $(n=5)$.

Hypothesis $\mathrm{H} 5$ posited that severity of cases using media supporting verbal communications would be more severe than cases using only media that support text communications. The richness construct provides a significant impact on case severity $\left(\mathrm{F}_{(2,773)}=6.525, \mathrm{p}=0.002\right.$, power at $\alpha=0.05$ is 0.908$)$, supporting the hypothesized effect. Hypothesis H6 posited that severity of cases using interactive media supporting real time communications would be more severe than cases using media that only support delayed communications. The test for a difference between real time and mixed cases (mean difference $0.070, \mathrm{p}=0.201$ ), and the comparison between delayed and real time cases (mean difference 0.006, $\mathrm{p}>0.999$ ) failed to show a significant difference of means. Finally, Hypothesis $\mathrm{H} 7$ postulated that the severity of cases using media supporting private communications would be more severe than cases using only media that support public communications. Unfortunately, the analysis failed to support a significant impact on case severity $\left(\mathrm{F}_{(2,772)}=0.492\right.$, $p=0.611$, power at $\alpha=0.05$ is 0.131 ).

\section{CONCLUSIONS}

To summarize, this research activity has proposed a novel and objective approach to measuring stalking case severity. This measurement process introduces a extension of the analytical hierarchy process that removes much of the subjectivity from the process, leading to an index value for each case that is largely objective. Using this measure of case severity, this analysis proposes looking at a number of factors associated with use of communications media by stalkers. An analysis over 1200 cyberstalking cases was conducted and while issues of relationship context and media richness were supported, others such as anonymity and channel expansion were not.

There are several limitations on the ability to generalize the results from this study. First, the data for this research comes from actual field cases, and was not initially collected by the researchers. Volunteer advocates working for WHOA summarized the cases in order to generate simple statistics for 
publicity and tracking purposes. There are substantial differences in the quality of the data as provided by the different advocates, and this is expected to introduce difficulties in coding, most specifically in the variables used to calculate the dependant severity variable.

Second, due to planned coding of the media usage variables in dummy form, there are substantial violations of the assumption of normality required for regression. To compensate, the most conservative tests available will be used for the analysis. Finally, estimation of power for the regression model is also affected by violations of assumptions of homogeneity of error variance. This will require the use of less powerful tests on the effects of some moderating classes, with an associated loss of control over Type II errors. Thus even with the size of this data set, not all moderating effects may be identified with this analysis.

This domain offers a real world environment in which to study the impact of information technology on cyber stalking behaviors. Cyberstalking is a very real threat and although the outcome may not be as severe as traditional stalking, information technology offers perpetrators new ways to further harass their victims. It is, indeed, a phenomenon worth further study.

\section{REFERENCES}

Adams, D. A., Todd, P. A. and Nelson, R. R. (1993). "A comparative evaluation of the impact of electronic and voice mail on organizational communication." Information \& Management 24(1): 9-21.

Alexy, E. M., Burgess, A. W., Baker, T. and Smoyak, S. A. (2005). "Perceptions of Cyberstalking Among College Students." Brief Treat Crisis Intervention 5(3): 279-289.

Bargh, J. A. (2002). "Beyond Simple Truths: The Human-Internet Interaction." Journal of Social Issues 58(1): 1-8.

Bargh, J. A., McKenna, K. Y. A. and Fitzsimons, G. M. (2002). "Can You See the Real Me? Activation and Expression of the "True Self" on the Internet." Journal of Social Issues 58(1): 33-48.

Berthold, O., Federrath, H. and Köhntopp, M. (2000). "Project "anonymity and unobservability in the Internet"." Proceedings of the tenth conference on Computers, freedom and privacy: challenging the assumptions, Toronto ON, ACM Press New York, NY, USA.

Bocij, P. (2002). "Cyberstalking: A New Challenge for Criminal Law." http://www.stalkingresearch.org.uk/index.php?Section=articles\&Page=articles Retrieved May 4, 2006. 
Brenner, S. W. (2004). "U.S. Cybercrime Law: Defining Offenses." Information Systems Frontiers 6(2): 115-132.

Brewster, M. P. (2000). "Stalking by former intimates: verbal threats and other predictors of physical violence." Violence and Victims 15(1): 41-54.

Carlson, J. R. (1995). 'Channel expansion theory: A dynamic view of media and information richness perceptions'. ProQuest Dissertations and Theses, Florida State University. Tallahassee FL, Unpublished Ph.D Thesis.

Connolly, T., Jessup, L. M. and Valacich, J. S. (1990). "Effects of Anonymity and Evaluative Tone on Idea Generation in Computer-Mediated Groups." Management Science 36(6): 689.

Cupach, W. R. and Spitzberg, B. H. (1998). Obsessive relational intrusions and stalking. The dark side of close relationships. Spitzberg, B. H. and Cupach, W. R. Mahwah, NJ, Lawrence Erlbaum: 233-263.

Cupach, W. R. and Spitzberg, B. H. (2004). The dark side of relationship pursuit : from attraction to obsession and stalking. Lawrence Erlbaum Associates, Mahwah, N.J.

D'Ovidio, R. and Doyle, J. (2003). "A Study on Cyberstalking Understanding Investigative Hurdles." FBI Law Enforcement Bulletin 72(3): 10-17.

Daft, R. L. and Lengel, R. H. (1986). "Organizational Information Requirements, Media Richness and Structural Design." Management Science 32(5): 554.

Dennis, A. R. and Kinney, S. T. (1998). "Testing media richness theory in the new media: The effects of cues, feedback, and task equivocality." Information Systems Research 9(3): 256-274.

Dziegielewski, S. and Roberts, A. R. (1995). Stalking Victims and survivors: Identification, legal remedies and crisis treatment. Crisis intervention and time-limited cognitive treatment. Roberts, A. R. Thousand Oaks, Sage Publications: 73-90.

Ellison, L. and Akdeniz, Y. (1998). "Cyber-stalking: the Regulation of Harassment on the Internet." Criminal Law Review, http://www.cyberrights.org/documents/stalking_article.pdf Retrieved May 23, 2006.

Emerson, R. M., Ferris, K. O. and Gardner, C. B. (1998). "On Being Stalked." Social Problems 45(3): 289-314.

Finn, J. (2004). "A Survey of Online Harassment at a University Campus." Journal of Interpersonal Violence 19(4): 468-483. 
Glaser, J., Dixit, J. and Green, D. P. (2002). "Studying Hate Crime with the Internet: What Makes Racists Advocate Racial Violence?" Journal of Social Issues 58(1): 177-193.

Goldberg, D. and Hillier, V. F. (1979). "A Scaled Version of the General Health Questionnaire." Psychological Medicine 9: 139-145.

Goode, M. (1995). "Stalking: The Crime of the Nineties?" Criminal Law Journal 19(1): 215-234.

Harmon, R. B., Rosner, R. and Owens, H. (1995). "Obsessional harassment and erotomania in a criminal court population." Journal of Forensic Sciences 40(2): 188-196.

Hian, L. B., Chuan, S. L., Trevor, T. M. K. and Detenber, B. H. (2004). "Getting to know you: exploring the development of relational intimacy in computer-mediated communication." Journal of Computer-Mediated Communication 9(3).

Horowitz, M., Wilner, N. and Alvarez, W. (1979). "Impact of Event Scale: A Measure of Subjective Stress." Psychosomatic Medicine 41: 209-218.

Kock, N. (2004). "The Psychobiological Model: Towards a New Theory of Computer-Mediated Communication Based on Darwinian Evolution." Organization Science 15(3): 327.

Kraut, R., Kiesler, S., Boneva, B., Cummings, J., Helgeson, V. and Crawford, A. (2002). "Internet Paradox Revisited." Journal of Social Issues 58(1): 4974.

McKenna, K. Y. A., Green, A. S. and Gleason, M. E. J. (2002). "Relationship Formation on the Internet: What's the Big Attraction?" Journal of Social Issues 58(1): 9-31.

Miceli, S. L., Santana, S. A. and Fisher, B. S. (2001). "Cyberaggression: Safety and Security Issues for Women Worldwide." Security Journal 14(2): 1127.

Miller, G. (1999). N. Hollywood Man Charged in 1st Cyber-Stalking Case. Los Angles Times. Los Angles, CA: 1.

Phillips, L., Quirk, R., Rosenfeld, B. and O'Connor, M. (2004). "Is it Stalking?: Perceptions of Stalking among College Undergraduates." Criminal Justice and Behavior 31(1): 73-96.

Purcell, R., Pathe, M. and Mullen, P. E. (2004). "Editorial: When do repeated intrusions become stalking?" Journal of Forensic Psychiatry and Psychology 15(4): 571-583. 
Roberts, A. R. and Dziegielewski, S. F. (2006). "Changing Stalking Patterns and Prosecutorial Decisions: Bridging the Present to the Future." Victims \& Offenders 1(1): 47-60.

Rosenfeld, B. (2004). "Violence Risk Factors in Stalking and Obsessional Harassment: A Review and Preliminary Meta-Analysis." Criminal Justice and Behavior 31(1): 9-36.

Rosenfeld, B. and Harmon, R. (2002). "Factors Associated With Violence in Stalking and Obsessional Harassment Cases." Criminal Justice and Behavior 29(6): 671-691.

Saaty, T. L. and Vargas, L. G. (2001). Models, methods, concepts \& applications of the analytic hierarchy process. Kluwer Academic Publishers, Boston.

Sheridan, L., Davies, G. and Boon, J. (2001a). "The Course and Nature of Stalking: A Victim Perspective." The Howard Journal 40(3): 215-234.

Sheridan, L., Davies, G. and Boon, J. (2001b). "Stalking: Perceptions and Prevalence." Journal of Interpersonal Violence 16: 151-167.

Sheridan, L., Gillett, R. and Davies, G. (2002). "Perceptions and Prevalence of Stalking in a Male Sample." Psychology, Crime and Law 8(4): 289-310.

Spears, R., Postmes, T., Lea, M. and Wolbert, A. (2002). "When Are Net Effects Gross Products? Communication." Journal of Social Issues 58(1): 91-107.

Spitzberg, B. H. (2002). "The Tactical Topography of Stalking Victimization and Management." Trauma Violence Abuse 3(4): 261-288.

Spitzberg, B. H. and Hoobler, G. (2002). "Cyberstalking and the technologies of interpersonal terrorism." New Media Society 4(1): 71-92.

Taylor, B. W. (2004). Introduction to Management Science 8th ed. Pearson Prentice Hall, Upper Saddle River NJ.

Te'eni, D. (2001). "Review: A Cognitive-Affective Model of Organizational Communication for Designing IT." MIS Quarterly 25(2): 251-312.

Thompson, L. and Nadler, J. (2002). "Negotiating via Information Technology: Theory and Application." Journal of Social Issues 58(1): 109-124.

Tjaden, P. G. and Thoennes, N. (1998). Stalking in America: findings from the National Violence Against Women Survey. NCJ 169592 National Institute of Justice and Centers for Disease Control and Prevention. Washington, DC: 19 pgs. 
Tjaden, P. G. and Thoennes, N. (2000). Full Report of the Prevalence, Incidence, and Consequences of Violence Against Women: Findings From the National Violence Against Women Survey. NCJ 183781 US Department of Justice, National Institute of Justice. Washington DC: 74 pgs.

Tyler, T. R. (2002). "Is the Internet Changing Social Life? It Seems the More Things Change, the More They Stay the Same." Journal of Social Issues 58(1): 195-205.

Walther, J. B. (1996). "Computer-mediated communication: Impersonal, interpersonal, and hyperpersonal interaction." Communication Research 23(1): 3-43.

Zigurs, I. and Buckland, B. K. (1998). "A theory of task/technology fit and group support systems effectiveness." MIS Quarterly 22(3): 313-334. 
Journal of Digital Forensics, Security and Law, Vol. 2(3) 